\title{
RESPUESTAS Y SUGERENCIAS
}

E. Pinilla de las Heras

Es más bien insólito que un autor comente un texto suyo con la intención de sugerir pautas de lectura. Empezaré, pues, por exponer algunas de las circunstancias que pueden justificar esta originalidad, ciñéndome en lo posible al caso particular de mi libro sobre Cataluña editado por el Centro de Investigaciones Sociológicas.

1. Primeramente, una precisión biográfica. La serie de investigaciones recogidas en Estudios sobre cambio social y estructuras sociales en Cataluña, son simultáneas de una crisis de la sociología académica en el mundo occidental. Este período de crisis podemos acotarlo entre dos obras de importancia para las reflexiones que los sociólogos nos vemos a veces obligados a hacer sobre el sentido de nuestro trabajo: el libro de Gouldner (The coming crisis of Western Sociology, edición en Londres en 1971), y seis años después el de Göran Therborn, Science, Class and Society (1976, 2. ${ }^{a}$ edic., Londres, 1977). Señalar este espacio cronológico equivale a decir que uno ha estado haciendo un trabajo empírico del género más académico en unos momentos en que se desarrollaba una ofensiva generalizada contra los análisis predominantemente técnicos a nivel «micro». Esta ofensiva se desplegaba en dos planos: por un lado, dentro del cuerpo de mandarines o teóricos; por 
otro, en el ámbito universitario de relaciones entre la ciencia social y las ideologías políticas.

En lo que concierne al primer aspecto, su carácter era en gran parte fundamentalista, en el sentido que tiene este término en el lenguaje académico anglosajón: es decir, de retorno moral a los fundamentos históricos de una doctrina o de una disciplina. No se dirigía tanto a señalar el despilfarro de energía intelectual y de dinero aplicados a descubrir, a través de costosas muestras microtomizadas en la computadora, relaciones estadísticamente significativas y a veces sociológicamente intrascendentes, como a postular una reorientación global de la tarea de los sociólogos. A mi entender, esta invocación para un retorno a las fuentes, constituye una manifestación de problemas mucho más de fondo que los ropajes morales e ideológicos que la envuelven y que forman el aspecto más visible de los argumentos de los invocadores. No se nos estaba diciendo: sed más prácticos, no gastéis tanto tiempo y tantos recursos (incluidos los monetarios) en demostrar cosas que ya saben $u$ os pueden decir los más perspicaces y más experimentados entre los actores sociales de cada contexto de análisis. Lo que se nos decía era en sustancia lo siguiente: ha habido un error en la construcción de teoría y en las dosis en que se han utilizado y mestizado las aportaciones fundamentales de unos cuantos grandes clásicos; hay que volver a ellos y redistribuir las dosis, de manera que formemos nuevos híbridos que sean más fecundos que los anteriores.

No se trataba, pues, de una oposición entre moral y economía, sino de argumentar en términos morales e ideológicos el problema del pobre nivel de acumulación de! conocimiento científico en sociología. Este problema es insoluble por la vía de los periódicos redescubrimientos de Hegel, o Marx, o Saint-Simon, u otro cualquiera de los genios del siglo pasado, y de la redosificación en que deben hallarse presentes en nuestras construcciones teóricas actuales. Este tipo de procedimiento (la hibridación cultural o formación de híbridos con fines de comprensión histórica) es propio de las disciplinas que en la época de la república de Weimar se llamaban ciencias de la cultura; y es desde luego sumamente fecundo para operaciones subjetivas de intelección histórica; pero añade muy poco al carácter acumulativo del conocimiento que distingue a las disciplinas científicas.

La biología, la física o la medicina no progresan por redosificaciones sucesivas de sus clásicos, sino por selección de problemas, por la definición de condiciones de pertinencia en los enunciados de esos problemas, y por el establecimiento de soluciones que están ligadas sistemáticamente y que pueden ser validables como las más pertinentes (en un nivel dado de desarrollo de cada campo de análisis).

En 1970, fecha en que empezaron a prepararse las investigaciones sobre Cataluña ahora reunidas en un volumen, apareció en la American Sociological Review un artículo de David Willer y Murray Webster, Jr., que he tenido en 
cuenta, en varios de sus aspectos, a lo largo del trabajo empírico de estos años. El hecho de que yo me sitúe ideológicamente en una posición muy distante de eso: autores no invalida el reconocimiento de la verdad de ciertas observaciones suyas. El tono anti-empirista y positivamente conceptualista de su artículo ' era reconocible como familiar para quienes en ese momento estábamos trabajando en el contexto académico francés, rodeados del clima de apogeo de lo que yo he llamado en otro lugar el absolutismo conceptualista althusseriano. Pero había una diferencia en esta enérgica llamada de atención anti-empirista según cómo estaba formulada a un lado o a otro del Atlántico. Mientras para los marxistas o soi-disant marxistas parisienses era poco menos que condenable como inútil o como ideológicarnente sesgado al servicio de la "ciencia burguesa» todo trabajo empírico realizado con las técnicas académicamente establecidas, los autores americanos lo que hacían era asumir este estadio e impulsarnos a trascenderlo; es decir, no renegar del poder analítico que nos otorgan las técnicas matemáticas en estadística, sino ir más allá de ellas ${ }^{2}$. Su observación sobre el uso de los modelos, tests y diseños de tipo Fisher, era particularmente relevante en mi caso, pues, como el lector del libro sobre Cataluña habrá visto, la práctica totalidad del aparato de análisis allí empleado consiste en análisis multivariables organizados en torno a técnicas tipo Fisher que quedaron establecidas definitivamente a principios del decenio de 1960.

El conceptualista que al mismo tiempo posee una fuerte experiencia en investigación y análisis, sabe que estas técnicas no se agotan con el manejo de coeficientes de asociación (que revelan por sí mismos únicamente la intensidad de una relación entre variables) y de tests de significación (que sugieren el potencial de universalidad o generalidad de una hipótesis). Sobre una masa de datos constituida por algo tan rudimentario como porcentajes, se pueden hacer otras operaciones de reordenamiento y descubrimiento de estructuras que tienen sentido sociológico; esto es, se pueden hacer inducciones de un interés social y mediante las cuales se manifiesta la presencia de determinaciones macrosociales en el comportamiento de variables definidas u obtenidas a nivel «micro». Esta experiencia nunca podrán alcanzarla los conceptualistas que no han hecho trabajo de investigación y análisis, y de los cuales son una subclase los marxistas o soi-disant marxistas que se encierran en el discurso puramente intelectual sobre las grandes determinaciones y la manera como se articulan entre ellas.

Todos sabemos que el trabajo científico consiste en descubrir lo que está oculto; pero no sólo lo que está oculto en las palabras. Por ello hay un conceptualismo que es tan estéril y tan poco acumulativo como las mediciones,

' David Willer, Murray Webster, Jr., Theoretical concepts and observables, A. S. R., vol. XXXV, núm. 4 (August 1970), págs. 748-757.

2 Ver en especial pág. 756, loc. cit. 
tests y coeficientes amontonados cuando no se posee previamente una idea de las determinaciones que se están buscando.

Esta adherencia ingenua a las palabras conduce al extremo de evaluar sumariamente un libro por las proporciones con que se citan Marx, Keynes - Parsons como palabras (indiferentemente de la pertinencia de la cita y del argumento). Se puede hacer una obra positivamente anticapitalista sin necesidad de citar ni una sola vez a Marx; y, desde luego, los crímenes del capitalismo en la época del imperialismo no serían menores aunque se diese el caso de que Marx no hubiera nunca existido. En este aspecto es muy oportuna una reflexión de Daniel Bertaux, en su último libro, sobre el modo en que Marx abso!vía de culpa a los capitalistas-persona ${ }^{3}$; porque la moral es ciertamente inseparable de determinados juicios científicos; pero por su lado, Marx tiene razón frente a Bertaux, en que un análisis científico debe sostenerse por sí solo, independientemente, de las personas.

Por ello mismo la actual crisis de la sociología no se resolverá, como dije antes, por la redosificación de los clásicos-persona. No se trata de citar más o menos a Marx o a Platón; es un asunto de criterios de pertinencia en la identificación de los problemas, en la formación de conceptos y en la relación entre éstos y el análisis.

Más de una vez, reflexionando o haciendo balance del diálogo con estudiantes, me ha asaltado de pronto el pensamiento de que quizá la sociología (o lo que conocemos bajo este nombre en el mundo académico de los países privilegiados en el Occidente capitalista) no llegaría a pasar el hito del año 2000. Esto es, que llegaría un momento en que se verá que carece de sentido dar vueltas en torno a un discurso que no es acumulativo, que apenas va más allá del descubrimiento de la sustantividad de lo social o de una objetividad diferenciada respecto a la psicológica individual y la económica general; y que : la larga la propia sociedad, sus dirigentes o quizá las organizaciones violentas derivadas de las clases o grupos más explotados no tolerarán una oratoria ociosa que consiste en recitar dos temas tan viejos como la humanidad: la legitimación de la dominación y la creación de historia por la lucha contra la dominación (i. e., la reproducción y el cambio).

Sin embargo. cuando uno está analizando los datos de una investigación, cuando se trata de un trabajo bien hecho, cuando uno ha empleado meses en construir un cuestionario y se han elegido cuidadosamente los encuestadores; cuando el código se ha fabricado con el máximo rigor semántico y lógico, y cuando uno recuerda constantemente los seres humanos que están debajo de todo ello y sus problemas reales, no sólo no se siente ese interragante de que la sociología sea en definitiva algo superfluo, sino que, por el contrario, se hace transparente su necesidad. Frente al discurso de la reproducción social en todas sus dimensiones («consensus», función de las élites, participación equilibrada en unos mismos valores culturales, etc.), uno

${ }^{3}$ Destins personnels et structure de classe, París, P. U.F., 1977, págs. 317-18. 
piensa en el tema mucho menos desarrollado de la racionalidad del cambio social y de la creatividad en la acción histórica. A menos que se opte por la creación de historia por la vía de la espontaneidad y la irracionalidad, la sociología es necesaria.

Pero para esto hace falta (como en cualquier otra disciplina con «status» científico ya adquirido o con pretensión de alcanzarlo) pasar muchas horas realizando trabaịos aparentemente rutinarios, ni más ni menos que los biólogos emplean mucho tiempo en contar leucocitos o en establecer la fórmula de una proteína. En el ejército de Bonaparte era verdad que cada soldado llevaba en su mochila un posible bastón de mariscal; en sociología es falso que cada estudiante sea en potencia un nuevo Marx.

Curiosa disciplina ésta, donde sus futuros profesionales rehúsan o desprecian el trabajo empírico, juzgado degradante servilismo idelógico o injusta agresión contra la capacidad del genio latente.

2. Con lo dicho hasta aquí queda explicado (o eso espero) por qué en el libro sobre Cataluña no hay un discurso propiamente político sobre el poder (burgués, por supuesto, porque hoy, en que ha desaparecido o se ha debilitado tan sensiblemente el poder del Estado, no hay en Cataluña otro poder que el de la clase económicamente dominante, que se está convirtiendo a la vez en políticamente dirigente). Con toda crudeza hay que decir que no participo de esa fascinación de las clases medias por el poder. Decía Locke que el poder es algo muy simple y que no conduce a nada darle vueltas intelectualmente. Como es obvio, ese punto de vista es propio de quienes han estado muy cerca del poder o han participado en él, es decir, se trata de una de las verdades sociales que de vez en cuando se obtienen de la clase más alta o de sus portavoces. También Maquiavelo sabía algo de esto. $\mathrm{Y}$ que el poder es algo muy simple (que, simplemente, se tiene o no se tiene) es algo que saben asimismo los proletarios por su experiencia de la lucha de clases en el suburbio industrial, en el latifundio o en la plantación. Son los sociólogos de clase media quienes han creído que hay un complejo misterio en el poder y que tal enigma va a ponerse al descubierto por razonamientos abstractos sobre las dimensiones del poder, sobre la articulación de sus instancias, su reproducción y otras palabrerías. Estos ejercicios intelectuales, híbridos de sociología y de lo que sus autores creen que es marxismo, no han enriquecido para nada el cuerpo teórico de la ciencia social y apenas han añadido tampoco nada que un observador perspicaz no supiera sobre la fuerza de la dominación burguesa en las sociedades occidentales de capitalismo avanzado. Al contrario, al pensar tantas «articulaciones» y tan bien trabadas entre sí, han concluido por asumir una especie de hiperfuncionalismo, donde todo aspecto de la sociedad está determinado por su función al servicio de la clase dominante. La fascinación por el poder (en 
abstracto) les ha conducido a una impasse intelectual, esto es, a un territorio que, crevéndose marxista, es completamente opuesto al marxismo. Si éste es una concepción global del movimiento de la historia, debe tomar distancia respecto a los imagos sociales que ven sólo la reproducción del poder y de la sociedad. Creer que la historia ha llegado a su fin es una de las quintaesencias de la ideología burguesa, como varias veces señaló Marx. Y percibir en la sociedad (incluso en la más tradicional, elitista, autoritaria y estatizada, como es el caso de Francia) simplemente la reproducción del poder capitalista y su multiplicación en diversas «instancias», no sólo significa asumir un hiperfuncionalismo burgués, sino algo más grave: estar ciego para las profundas transformaciones sociales y redistribuciones de poder latente, entre clases, que ha habido a lo largo del ciclo de prosperidad capitalista que va desde 1949 a 1975 . La fascinación por la reproducción del poder político del capitalismo les oculta la observación de lo sociológicamente importante: los cambios en la estructura de clases y las mutaciones económicas dentro del capitalismo.

3. A causa de un conjunto de factores cuya acción ha sido positiva en favor del desarrollo económico y la elevación de los niveles de consumo, la sociedad catalana ha participado intensamente de algunos procesos sociales que caracterizaı también la historia social de otras áreas europeas industrializadas. La pobre presencia del Estado (salvo como agente fiscal), la inexistencia de problemas derivados de balances de pagos deficitarios con el exterior (que han sido, y son, la pesadilla de otros Gobiernos europeos) $\mathrm{y}$, por tanto, la inexistencia de tensiones económicas y sociales creadas desde arriba, desde una autoridad pública, para obtener en breves períodos de tiempo mayores niveles de eficiencia en el sistema productivo, constituyen (entre otros) rasgos de un sistema social que ha permitido una vida muy vigorosa en la sociedad civil.

La debilidad de los poderes públicos y la fuerza de los poderes privados es algo que aparece constantemente, entre líneas, a través de los análisis numéricos. En este aspecto hay que saber leer detrás de las estructuras de porcentajes e ir más allá de los «tests» y los coeficientes (que no son más que puntos de apoyc técnicos para saber que pisamos terreno firme en la dimensión estadística). Sin imaginación sociológica, sin una memoria permanente de lo que es una sociedad de clases, un libro como éste sobre Cataluña no es más que una masa de datos organizados en índice de materias.

Una sociedad que se autovisualiza como abrumadoramente de clases medias revela la intensidad de sus divisiones sociales internas. No es cierto que en la medida en que la inmensa mayoría de la población es portadora del atributo asalariado (es, o se presenta, como trabajador por cuenta ajena), la sociedad se haga más homogénea. La idea que en Francia defienden los intelectuales o políticos liberales (y particularmente M. Michel Poniatowski en 
sus últimos libros), según la cual la sociedad capitalista liberal avanzada contará con dos grupos residuales mínimos (campesinado y proletariado industrial) y una gran masa central para la cual ya no es pertinente el concepto de estructura de clases o de división de clases, se revela evidentemente como no fundada, cuando examinamos los resultados de investigaciones sobre una sociedad en bastantes puntos afín a la francesa como es la catalana. La gente reconstruye las divisiones de clase, y las distancias sociales subjetivas son hoy tan fuertes como en el siglo XIX, aunque aparentemente carecen de una base económica objetiva homóloga. Pero no sólo se reconstruyen las distancias subjetivamente; también lo son objetivamente. Lo que sucede es que carecemos de los instrumentos inmediatos y adecuados de análisis social, e incluso de los indicadores más directos. Disponemos de datos sobre el abanico de salarios, pero no hemos ido a los registros de la propiedad, a las notarías, o a las valoraciones sistemáticas de las transmisiones de bienes post-mortem, establecidas sobre muestras representativas de la población.

La elevación general del nivel de vida y el acceso común (o casi común, excepto para una minoría en situación de marginalidad y de miseria) está ocultándonos la construcción de patrimonios considerables, de divisiones y distancias de furtuna y, como me señalaba asimismo recientemente un antropólogo norteamericano de la Johns Hopkins Univ. trabajando sobre Cataluña, la decadencia de algunas de las grandes familias del antiguo patriciado urbano de Barcelona.

Lo que ocurre es que estos procesos de redistribución de riqueza y de redefinición de la estructura de clases sobre otros ejes clasificatorios que los del siglo XIX, son hoy menos visibles y demandan métodos analíticos ad boc. Porque no se manifiestan escandalosamente en la superficie, se piensa que no existen. Quizá los historiadores sociales pondrán un día en claro la magnitud de este error.

Un sociólogo debe actuar a veces como el paleontólogo, haciendo deducciones e inferencias a partir de unos pocos objetos o indicadores disponibles. En este aspecto, el libro sobre Cataluña contiene los elementos suficientes para sugerir la falsedad de una serie de imágenes e ideologías convencionales sobre la sociedad liberal avanzada. Las diferenciaciones entre clases medias y la clase obrera emergen de un modo rotundo. La comunidad de intereses económicos de ambas, frente a las clases más altas o frente a la burguesía propietaria, se rompe en forma de distanciación política de la clase media respecto a la clase obrera. Ambas van juntas en la promoción de sus respectivos ingresos; pero las clases medias valoran muy alto su autonomía en el trabajo, su nivel cultural, su acceso a la información, su monopolio de determinadas lecturas; y basta observar los lenguajes con que se refieren a la clase más baja (y los porcientos sobre uso de términos que denotan privación económica o social) para advertir desde qué altura social se reconstituyen las fronteras de clase. 
4. Todos estos procesos que permanecían soterrados, irrumpen ahora a la luz cuando se forma un sistema político ex novo. La clase obrera se halla con voto pero sin voz en el asunto, porque se le otorga el derecho de votar, como sus representantes, a los miembros de otras clases. Se da así la recreación de un sistema político como los del siglo XIX o los anteriores a la segunda guerra mundial en sociedades bastante elitistas y tradicionales. No hay obreros representando a obreros. Los partidos políticos son oligarquías con una enorme diferenciación social entre sus dirigentes y sus clientelas. La función de control sobre las bases es no menos importante, o quizá más importante en su direccionalidad específica, que la función de representación. La expulsión, prácticamente consumada, de la lengua castellana como vehículo de registro de las decisiones políticas y medio de debate entre los dirigentes, sobredetermina la diferenciación social que trasciende a política. A veces el observador piensa que se reproduce en Cataluña el sistema de las dos naciones denunciado en Inglaterra por Disraeli; o, en términos más técnicos, un sistema político que se organiza sobre principios que habrían suscrito Alexander Hamilton o Walter Bagehot. La crisis económica y el retorno al liberalismo económico (que implica la ley del más fuerte) con el abandono de las funciones paternalistas que usó el franquismo para legitimar (entre otros medios) su dominación política, agravan sin duda la situación de la clase obrera.

La extensión de las libertades burguesas y el hecho de que éstas sean llevadas hasta sus últimos límites, deja poco menos que indiferente a la clase obrera: hay que disponer de mucho tiempo libre, ocio y dinero, para gozar de esas libertades burguesas; el trabajador que entra a las siete de la mañana en la fábrica y vuelve a casa a las ocho de la noche, no es el beneficio de la liberación de costumbres, ni de las audacias de expresión en los medios de comunicación, o de la libertad de asociación política (que es asunto sobre todo de los abogados excedentarios que producen las Facultades de Derecho y ahora no encuentran empleo suficiente en el sector privado). El trabajador no es hostil a la liberalización ni a la extensión de las libertades burguesas; pero éstas no le atañen en sus problemas vitales.

$Y$, dado que un país no vive de las libertades burguesas sino de la eficiencia de su sistema productivo y de su capacidad para ocupar un lugar que le sea favorable en la división internacional del trabajo, la observación anterior es pertinente no sólo para la clase obrera, sino para la generalidad de la sociedad.

Es dentro de este contexto como deben ser leídas las conclusiones del libro, donde el autor no ha podido (desde luego) superar sus propias contradicciones. Pero éstas son, en buena parte, intrínsecas a la ambigüedad de la situación histórica que viven tanto Cataluña como el resto de España.

La necesidad de profundizar la democracia y hacerla real para todas las clases, y no sólo para unos grupos de profesionales de la política (como dice 
muy bien J. Vidal Beneyto en Le Monde diplomatique, de septiembre de 1979), nos sugiere que no es por la vía del retorno al autoritarismo y el reforzamiento del Estado como ese incremento de la participación democrática podría conseguirse. Pero equé sentido puede tener, a más largo plazo, una democratización que eduque a los políticos profesionales y a sus querellas de «nacionalidades» y de repartos de poderes y de recursos fiscales, en un país cuyo sistema económico pierde eficiencia y depende cada vez más de los centros imperialistas extranjeros? ¿Qué significa la libertad política local en un sistema de creciente dependencia económica? ¿Puede el Estado contribuir aún a la preservación de una autonomía económica y política, como ha sido el caso en Francia bajo las presidencias de De Gaulle y de Pompidou, con resultados de los que se beneficiaron todas las clases sociales, bajo la dirección de una minoría de expertos que en la jungla internacional defendían los intereses nacionales franceses? ¿Cuenta España con unos equipos de expertos comparables para ese tipo de lucha?

En 1974 concluyó en Europa occidental (y hacia $1975-76$ concluyó en Cataluña) un modelo de desarrollo económico basado en la industrialización extensiva en mano de obra y en el despilfarro de la sociedad de consumo. Los países de más alto nivel tecnológico, como la República Federal Alemana, Suiza, Países Bajos, etc., vieron en seguida que había terminado para siempre una etapa del desarrollo capitalista. Los trabajadores emigrados fueron los primeros en sufrir las consecuencias: por centenares de miles tuvieron que regresar a sus países de origen o redistribuirse en otras economías que no reaccionaron a la crisis con la misma agilidad. En Suiza la población extranjera descendió del 18 por 100 de la población total en 1973 al 13 por 100 en 1976. Desde entonces se ha ido perfilando cada vez con mayor nitidez una nueva división internacional del trabajo consistente en la reestructuración de los sistemas productivos en los países hegemónicos y en la extensión de la industrialización en el Tercer Mundo, allí donde se dispone de recursos propios de energía (Nigeria, Venezuela, México, etc.). Las localizaciones mundiales de la industrialización están siendo redistribuidas. Este proceso implica, en Europa occidental, la reducción de los puestos de trabajo industriales y la expansión de los correspondientes a servicios, en particular los servicios financieros, bancarios, los relacionados con las mutaciones tecnológicas, con el comercio exterior y con la industrialización «a distancia» (es decir, la internacionalización del capital).

En Cataluña aparecieron ya indicios de la existencia de este proceso en los años finales de prosperidad bajo el régimen franquista; empresas catalanas se establecieron en el sur de Francia y en algunos países de América. La experiencia ulterior ha demostrado, empero, que este tipo de proceso requiere contar con unos recursos financieros y tecnológicos, y con unos equipos de ejecutivos de alto nivel de competencia, en un grado mucho mayor de los que se dispone por estas tierras. De las empresas catalanas que se instalaron 
en el mediodía francés al amparo de las facilidades concedidas por la Datar (Délégation pour l'aménagement du territoire et l'action régionale) quedan sólo dos o tres. En este momento en que empresas catalanas se instalan en Venezuela o en República Dominicana, uno se pregunta si no sería más inteligente la alianza entre burguesía catalana y Estado para la industrialización interior del resto de España, donde todavía existen recursos humanos excedentarios en la sociedad rural y una fuerza de trabajo por emplear (alimentada por las altas tasas de natalidad que estimuló el régimen franquista).

Este tipo de contradicciones sobre el rol futuro del Estado son las que se reflejan en las páginas finales de mi texto, espejo de la encrucijada a que ha conducido a España la imposición urgente de problemas artificiales como el de las llamadas "nacionalidades». Por haber sido testigo en Francia del disfuncionalismo y la represión de energías creadoras que implica el estado jacobino y centralizado, soy muy consciente de los valores de un Estado de autonomías; pero la destrucción del patrimonio cultural común y la multiplicación de burocracias locales para sólo provecho de los licenciados en Derecho que la crisis económica no permite ahora emplear en las empresas privadas, son precios que hay que tomar en cuenta. Los españoles son grandes destructores, dice Gerald Brenan en el Laberinto español; habría que añadir que son, sobre todo, destructores cuando se convierten inconscientemente en títeres de intereses imperialistas extranjeros. Un país con radicales divisiones internas, sin ningún espíritu de solidaridad y comunidad, se convierte fácilmente en terreno de ensayo para los poderes que se disputan el dominio del mundo. Unas veces se ensayan aquí nuevos armamentos (como fue el caso durante la guerra civil última), y otras veces se ensayan sistemas ideológicos, mediante los cuales se pueden balcanizar y destruir Estados.

De estas evidencias (que tantos españoles no quieren ver, cegados por un tribalismo reaccionario) deviene la ambigüedad que es visible en las últimas páginas de mi texto, en lo referente a la función del Estado y a las relaciones de la clase obrera con el aparato estatal. Sencillamente, se trata de percatarse de factores actuantes y que nos afectan a todos, más allá de las luchas lingüísticas por la toponimia de las calles y la conversión en apátridas sin nación de figuras como Cervantes, Velázquez, Goya o San Juan de la Cruz. Se trata de que aquí, en unos momentos en que la burguesía se internacionaliza y parece adaptarse de buen grado a las funciones de cumplidora de roles asignados por los centros hegemónicos imperialistas, la sola clave verdaderamente nacional es la clase trabajadora, esto es, el proletariado industrial y el campesinado.

Quizá debieron las cosas ser dichas así, en vez de extenderse en disertaciones académicas sobre la democracia ficticia que se constituye en Cataluña y la no transcripción, en el sistema político, de los verdaderos interlocutores sociales. 
La cuestión de fondo está en otra parte. ¿Se cree verdadera y honestamente que van a ser las fuerzas espontáneas del mercado las que asignen empleo a las nuevas generaciones que están llegando, supernutridas por una natalidad excesiva, al mercado de trabajo? ¿Se tiene una idea y unos planes para la industrialización de España todavía por hacer? ¿Sabe la insaciable burguesía de Barcelona si puede, y quiere, contribuir a esa industrialización conciliándola con una cierta mutación de la tecnología y de los servicios en Cataluña? ¿O van a ir cada mini-Estado autónomo por su camino propio, atraídos por el espejismo de sociedades mucho más desarrolladas y cuyo nivel científico, cultural y tecnológico estamos aquí aún muy lejos de asumir? 


\section{CRITICA DE LIBROS}

